University of Montana

ScholarWorks at University of Montana

\title{
Considerations and Challenges for Describing Historical Research Data: A Case Study
}

Teressa M. Keenan

University of Montana - Missoula

Wendy Walker

University of Montana - Missoula, wendy.walker@umontana.edu

Follow this and additional works at: https://scholarworks.umt.edu/ml_pubs

Part of the Library and Information Science Commons

Let us know how access to this document benefits you.

\section{Recommended Citation}

Teressa Keenan \& Wendy Walker (2018) Considerations and Challenges for Describing Historical Research Data: A Case Study, Journal of Library Metadata, 17:3-4, 241-252, DOI: 10.1080/ 19386389.2018.1440919

This Article is brought to you for free and open access by the Mansfield Library at ScholarWorks at University of Montana. It has been accepted for inclusion in Mansfield Library Faculty Publications by an authorized administrator of ScholarWorks at University of Montana. For more information, please contact scholarworks@mso.umt.edu. 


\section{Considerations and Challenges for Describing Historical}

\section{Research Data: A Case Study}

Running head: Describing Historical Research Data

Authors: Teressa Keenan - Head Bibliographic Management Services/Metadata Librarian; Maureen and Mike Mansfield Library, University of Montana; teressa.keenan@mso.umt.edu

Wendy Walker - Digital Initiatives Librarian; Maureen and Mike Mansfield Library, University of Montana; wendy.walker@mso.umt.edu

\section{Abstract}

This case study describes the several challenges faced by Library personnel at the University of Montana as they iteratively made an historical dataset available in the institutional repository in a way that attempted to optimize its discoverability, accessibility, searchability, and usability to current and future researchers. The authors will examine the development of this multi-media dataset collection in order to discuss the specific challenges and opportunities around: describing and making available an historical dataset, repository structures, metadata specifications, and accessibility requirements.

Keywords: Historical data, Digital Commons, Seismic data, Data enhancement, Data description, Accessibility, Data dissemination

\section{Introduction}

As libraries begin to investigate and expand their roles related to research data management services and data curation they are adding more datasets to their collections. Data can be purchased or licensed 
similarly to electronic journals; retrieved via open access data repositories; or collected and stored locally in an institutional repository (IR). Like many new and exciting opportunities, data collection and curation also bring challenges. One of those challenges is how best to describe and provide access to datasets, particularly for small- and medium-sized libraries that may not have specialized staffing, such as a librarian with research data management responsibilities, or abundant resources. In this article the authors will share, using a case study, their experience with providing access to a set of historical seismic data.

\section{Literature Review}

With the global increase in research data output and the progressive move of funding agencies and scholarly journals towards requiring data management plans and open sharing of data, there is no question that interest in research data management is increasing (Perrier et al., 2017). There is an ever growing amount of information about the role of academic libraries in research data management (Chiware \& Mathe, 2015; Lage, Losoff, \& Maness, 2011; Newton, Miller, \& Bracke, 2010; Yu, 2017) and the curation of research data and the data lifecycle in general (Gonzalez \& Peres-Neto, 2015; Poole, 2016; Schubert, Shorish, Frankel, \& Giles, 2013; Yu, Deuble, \& Morgan, 2017).

A vital element of research data curation is metadata management; every "activity associated with data curation requires the use of different types of tools and metadata to describe, administer, and package research data" (Lee and Stvilla, 2017, p. 3). Lee and Stvilla (2017) also point out that while metadata quality and reusability in general is prevalent in the literature, "there is a shortage of research on uses and practices for research data in the context of IR's" (Literature review section, para. 4). The authors found this to be true when looking for guidance on how best to add a collection of seismic data to the University of Montana's Digital Commons-based IR, ScholarWorks. 
Another developing area under exploration in the library literature centers on metadata and accessibility. The research discusses the intersection of metadata and accessibility in two different ways. "Accessibility metadata" has the potential to improve knowledge discovery and access in digital library environments and can be instrumental in exposing accessible resources to users with print disabilities (Beyene, 2017; Chapman et al., 2006; Morozumi, 2006). It tends to focus on metadata that describes accessibility features of online resources, such as closed-captioned video or audio transcripts that enable users with print disabilities to understand if and/or how they may be able to use a resource. A related but distinct area of research discusses how and what kind of specific traditional metadata supports the accessibility of online resources for users with print disabilities (Byene \& Godwin, 2018; Keenan, 2014). In the context of this case study, the authors' discussion of accessibility tends to align more closely with the latter area of research; however, questions about accessibility metadata do arise, as do questions about accessible data more broadly.

\section{Background}

The University of Montana (UM), founded in 1893, is a co-educational, doctoral institution, serving a student population of approximately 13,000 (“About," n.d.). UM is classified as a Research University and is located in Missoula, a city in the northwest part of the state hosting a community of nearly 60,000. Part of the Montana University System, UM is a multi-campus university, with three affiliated campuses (UM Western in Dillon, UM Helena College of Technology in Helena, and Montana Tech of UM in Butte). The Maureen and Mike Mansfield Library (ML), on the Missoula campus, has the largest library collection of books and media in Montana. Collections exceed 1.5 million volumes; including over 30,000 print and electronic journals and hundreds of electronic databases, federal government document repository collection and an archives and special collections ("Collection development," 2011). 
In 2008 the Mansfield Library accepted a gift of original research data from a 1970 Flathead Lake seismic survey. The dataset, which comprised both paper and digital files, included a variety of data types, from audio, images, and text-based documents to seismic data files. At the time the data were donated, the Library did not have a suitable means of making the dataset available to the public. The data were stored in the Archives and Special Collections Department until a solution could be found.

In 2010-2011 the Library began considering the implementation of an IR. Library staff installed DSpace and a couple of librarians began uploading small batches of content in order to test and evaluate the software. Many of the digital image files from the seismic survey were uploaded to DSpace as part of this pilot evaluation. In fall 2013, approximately eight months after the arrival of the current Digital Initiatives Librarian and after extensive evaluation of both DSpace and bepress' Digital Commons, the Library launched a Digital Commons-based IR, ScholarWorks, which would provide the final means for making the data available.

\section{Challenges}

\section{Historical nature of the data}

The 1970 Flathead Lake Seismic Survey project represented the Library's first experience with hosting and providing access to research data in the newly-minted IR, and as such, it posed several challenges for the librarians involved in presenting and describing it.

The first challenge arose immediately: Neither the principal investigators nor the Library personnel involved with the initial upload of test files to DSpace were available for consultation. Furthermore, the data were not accompanied by detailed notes or descriptions. Any original documentation that may have been created had become lost over time. The initial upload of digital image files to DSpace had 
included minimal metadata, based solely on filenames and handwritten labels on DVD cases. Because the data had represented a test case in DSpace, Library personnel had not been too concerned about the completion or accuracy of the metadata they included. The inclusion of these data in the new IR, however, demanded better and at least accurate metadata; however, neither the Metadata Librarian nor the Digital Initiatives Librarian had expertise in the subject area of seismic data or geology. In the end, there simply was not enough extant information about the data to enable the Metadata Librarian to understand and adequately describe the data.

Luckily, Dr. Bob Lankston, an interested researcher and former officemate of one of the Survey participants, was familiar with the data. He pieced together the history of the data for the librarians. In addition, with his background and experience as a geoscientist, he was able to craft text-based narratives that provide important contextual information for the data.

The process of creating these narratives became quite iterative. Initially, the librarians provided only very general guidance to Dr. Lankston for writing the narratives. Relying on his domain knowledge and expertise, they simply asked him to provide as much information as possible about the data and about his knowledge of the data's use since its collection in 1970. Dr. Lankston submitted drafts of a few of the narratives, which clearly demonstrated his aptitude for writing and for including detail, along with questions about the narratives' content. The writing and revision process developed into an ongoing conversation between Dr. Lankston and the librarians as the librarians answered Dr. Lankston's questions based on their knowledge of bibliographic and metadata elements that help improve discoverability and understanding of digital resources. 
The resulting narratives provide information, such as the rationale for the structure and presentation of the data in the IR; information about the location of the Survey; informed speculations about equipment and procedures used during the Survey; and information about Dr. Lankston's work with the data and some of the transformations applied to the data, such as digitization and reformatting of some of the analog and digital seismic file types, that helps make the data understandable and usable by other researchers. References to discipline-specific file formats, terms and language, and seismic surveying equipment help facilitate discovery by researchers working in or familiar with the discipline. The quality of Dr. Lankston's writing helps facilitate discovery and comprehension by non-experts.

\section{Presentation of the data in the IR}

While Dr. Lankston wrote the narratives, Library personnel grappled with decisions about how best to present the data within the repository. At the time, the Digital Initiatives Librarian was still learning the basic features and functionality of Digital Commons, so this dataset, with images, audio, text, and seismic files of a type she had not previously seen, presented a challenge. What kind of organization of the files would make the most sense to potential users and viewers of this data? Digital Commons provides several different kinds of back-end structures (image gallery, series, book gallery, etc.) for making content available. Which structure would accommodate these files in an optimal way while also accounting for whatever organization, independent of the repository, seemed best?

Once again, Dr. Lankston provided much needed assistance. He recommended the organization of the data by type, which in this case, meant breaking out the files into bathymetry and survey lines, fieldrecorded seismic sections, bathymetry profiles, redisplayed seismic sections, interpretation cross sections, written notes from 1980 that assessed the 1970 data, sound files, and code and instructions for converting the sound files to standard seismic file types. A map of the Flathead Lake area where the original data were collected and an introductory narrative rounded out the final collection in the IR. 
After conferring with UM's bepress consulting services representative, the Digital Initiatives Librarian selected the book gallery in Digital Commons as the best structure for the data because it is designed to accommodate items that contain multiple separate but related parts both at a collection and item level. The book gallery provided the most suitable framework for the many data files and for Dr. Lankston's accompanying narratives and nicely accommodated his recommended organization of the data. Automatically-generated cover pages for the primary files in the book gallery, which are Dr. Lankston's narratives, include a link back to the entire dataset in the repository, an easy way to direct researchers to the data in the IR if they find one of the searchable, text-based narratives first.

\section{Metadata development}

With the book gallery in place, the Digital Initiatives and Metadata Librarians began discussing metadata for the data. Several circumstances complicated this step. First, Digital Commons only supports Dublin Core metadata, so the metadata profile for the data needed to adhere primarily to the Dublin Core schema. It is possible to add customized fields to Digital Commons, but if they do not map to a Dublin Core element they are somewhat less useful in terms of interoperability (Pesce, 2015). Both librarians had configured and used CONTENTdm, so they were at least familiar with Dublin Core.

Second, even though each book in the book gallery would include different kinds of data, each book in a Digital Commons book gallery must include the same metadata fields. While the librarians did not need to use each field for each book, the underlying architecture of Digital Commons remained a factor in the final decisions about the metadata. 
Third, and perhaps most significantly, the librarians at that time were just beginning to learn about research data management services and related issues for libraries, including emerging metadata standards for different disciplinary data. In an effort to find guidance on how best to apply metadata to the collection, the Metadata Librarian first looked to traditional resources, such as Resource Description and Access (RDA) and MARC 21 Format for Bibliographic Data, the rules and guides with which she was most familiar. While this approach provided useful information on how best to describe identifying elements of datasets in a traditional library catalog, specific data elements beyond basic bibliographic information such as creator/contributors, title, etc. was not easily identified and applied to the basic Dublin Core framework in the IR. Nor did it identify what kind of information might be useful to include for researchers who might want to use the data.

Together, the librarians' nascent knowledge of metadata for research data and the design and structure of Digital Commons in terms of metadata support drove the librarians towards a fairly basic Dublin Core metadata profile for the data. It seemed prudent to use fewer rather than more metadata fields for other reasons as well, including ease of documentation and long-term maintenance of the collection in the IR; the provision of the searchable narratives by Dr. Lankston, which provided metadata in a narrative form; and the fact that so much information about the data that might have been included in the metadata fields was missing or could only be conjectured. Even looking at the data today, the fact that definitive information about the recording system and field procedures used for the Survey remains missing complicates the direct application of existing metadata standards used by known repositories containing seismic data such as the National Geological and Geophysical Data Preservation Program (USGS, 2017), the Extended Continental Shelf Project (National Geospatial Data Center, n.d.), and Interpreted Seismic and Well Data (British Geological Survey, n.d.). 
Finally, this project was just one among many for both librarians, and Dr. Lankston's eager assistance with the contextual narratives and with the data in general made a detailed metadata profile for the dataset seem somewhat unnecessary. Granted, fewer metadata fields may make the collection less interoperable with other systems to some degree, but the librarians ultimately agreed that for the time, the searchable narratives and basic metadata would suffice.

In the end, the descriptive metadata included the following elements: title, creators, description, date, subjects, and recommended citation. These elements correspond directly to a Dublin Core element with the same name with the exception of the recommended citation element, which is not mapped to a Dublin Core element. The Digital Commons book gallery also provides a list of the downloadable files that includes the file size. This group of metadata elements applied to all of the books in the collection regardless of file format or data type. At the time, the narratives and this basic set of metadata fields appeared to be a "good-enough" combination of metadata that would meet the basic needs of the research community interested in historical seismic data. The traditional metadata provided a basic description of all the parts of the collection in a consistent manner, and the narratives, which are searchable via search engines, provided needed details for researchers as well as an additional means of discovery.

\section{Accessibility}

While sorting out how to make this historical, seismic research data available in the IR in a useful way with sufficient metadata, the librarians encountered another issue related to accessibility. The University of Montana adopted a campus-wide Electronic and Information Technology Accessibility policy in spring 2014. It required all web sites and online documents to be compliant with the World 
Wide Web Consortium's (W3C) Web Content Accessibility Guidelines (WCAG), version 2.0. How accessible can seismic data be?

Answering this question proved challenging as electronic accessibility was another new knowledge domain that the librarians had just begun to explore. They started with Dr. Lankston's narratives, which were composed in Microsoft Word and saved as PDF files. As such, they were readable by screenreading technologies and fully searchable. The librarians relied on these narratives again to stand in as the alternative text for the many images in the dataset. According to WebAIM, "alternative text for images is the first principle of web accessibility" ("Introduction," 2017). The narratives, valuable on their own for the descriptive metadata and context they provide, albeit in a non-traditional way, became even more valuable when viewed through the lens of accessibility. While they do not precisely describe the images in the collection, they do at least provide information about what the images convey. Guidance on best practices for describing specific complex images such as relational diagrams, graphs, maps, etc. is provided by the DIAGRAM Center, however images such as bathymetry profiles and seismic sections are not included ("Image description," n.d.). The librarians remain unsure about how to describe the seismic image data in a truly effective way for users with disabilities.

The sound files in the data collection presented a particularly interesting challenge for the librarians as they do not include words that can be transcribed. On the one hand, they remain inaccessible to some users with auditory disabilities. On the other hand, as Paolo Dell'Aversana noted "Currently, the beauty of geoscience is at least partially precluded to blind people. Adding a sound dimension could represent a less exclusive (and more democratic) way to practice the Earth disciplines" (2013). Dr. Lankston summarized Dell'Aversana's proposition in this way: 
In the August 2013 issue of The Leading Edge (TLE) the scientist (Paolo Dell'Aversana) has an article in which he discusses turning .wav and .mp3 files of seismic recordings into "music". He uses common software to make sheet music out of the seismic data and also to make MIDI files. The sheet music images and images of MIDI files give an interesting look at the geophysical data. He also notes that he is not promoting that his technique supplant any traditional interpretation procedures, but he speculates that one never knows just what one will see when looking at things from a different viewpoint. Once he has the MIDI file, he plays the file through a synthesizer. He chooses various instruments to emphasize certain elements of the "music", like violins for high frequencies and drums (I suppose) for low frequencies (personal communication, August 21, 2013).

If Dell'Aversana is correct, the sound files in this dataset, while inaccessible to some users with auditory disabilities, actually expand access to some users with visual impairments, which the librarians find both interesting and exciting. Someone who may not be able to see the seismic images may be able to hear the seismic data. The librarians would have preferred to make all the digital data accessible to all users, but when it was not possible to do so, they chose to expand access to more users than to deny access to all.

Finally, and inevitably, the IR platform and the way metadata is exposed in it became a focal point for inquiry in terms of accessibility. The librarians reviewed bepress' Voluntary Product Accessibility Template (VPAT) as well as the Accessibility Statement linked in the Digital Commons footer. At the time they agreed, and a later user study that they conducted confirmed, that Digital Commons is a sufficiently accessible repository. Among other accessibility features, it includes navigational headings and breadcrumbs as well as descriptive links; provides keyboard shortcuts that are not tied to a specific 
screen reader; and displays well-structured metadata that is easy to locate, navigate, and understand (Walker \& Keenan, 2014). Digital Commons meets the primary criteria outlined in the W3C WCAG, version 2.0 (2008).

\section{Lessons Learned}

In the process of making the Flathead Lake Seismic Survey data available in the IR, and in the process of reflecting on it, the librarians learned a number of valuable lessons.

1. Librarians can provide good access to research data with Digital Commons. Multiple features in the repository help optimize the delivery of data, including the automaticallygenerated cover pages for primary files that help direct users back to the data within the repository and the different back-end structures in Digital Commons that provide solid frameworks for organizing and presenting all kinds of data types and discrete data files.

Having said that, Digital Commons requires the use of the Dublin Core metadata element set. As they have learned more about metadata for research data, the librarians question the adequacy of Dublin Core for describing seismic data, particularly in light of recommendations such as those from the U.S. Extended Continental Shelf Project (National Geospatial Data Center, n.d.). While the librarians realize that they did not take full advantage of the Dublin Core metadata schema in the IR and could improve the metadata by adding fields such as geographic coverage, original and digital formats, and rights information, they wonder if the restriction to Dublin Core presents challenges to librarians at other institutions who want to make full use of some of the very rich discipline-specific metadata profiles for research data that have emerged over the last 
several years. Furthermore, the librarians find the inability to easily view the Dublin Core field mappings in Digital Commons frustrating. Documenting metadata decisions and mappings for Digital Commons projects remains quite useful.

2. The knowledge and skills of traditional cataloging are useful as a framework that can be applied to developing metadata for research data; however, this knowledge is not enough on its own. It is important to look beyond traditional cataloging and metadata resources as well as beyond the library and the library literature to research data management organizations such as the Research Data Alliance, DataONE, the Digital Curation Centre, and the Data Documentation Initiative (DDI) Alliance. These organizations focus on research data management and create or point to discipline-specific metadata profiles and description as well as best practices for research data management in different fields.

3. If a metadata profile or schema for a particular dataset cannot be located or adequately adapted for a local repository, one or more alternative approaches to creating descriptive metadata may be employed. Seek guidance or assistance from an outside expert. Accept descriptive metadata in non-traditional formats. The narratives discussed in this case study remain valuable both for the context and information they provide and because they improve the accessibility of the data. In this case, in particular, the narratives help fill in the gaps in terms of missing metadata and in that way, exist as a kind of long-form metadata themselves.

For historical datasets or for datasets without accompanying documentation about research methods, Chao (2015) proposed another method for creating descriptive metadata. She investigated: 
research journal publications as a potential source for identifying descriptive metadata about methods for research data. Initial results indicate[d] that journal articles provide rich descriptive content that can be sufficiently mapped to existing metadata standards with methods-related elements, resulting in a mapping of the data production process for a study (p. 82).

Chao's study focused on soil ecology; Ferguson (2012) explains a similar approach for describing biomedical datasets. Finally, in some cases it may be possible and worthwhile to create an entirely new metadata model for a particular dataset (Qin, J., Dobreski, B., \& Brown, D., 2016).

Creating metadata for datasets can be challenging, but it is crucial for discovery, access, re-use, reproducibility, and preservation. It is also worth noting that Chao and Qin et al. published in the International Journal of Digital Curation, while Ferguson published in the Journal of eScience Librarianship, which underscores the statement in the previous point about looking beyond traditional cataloging and metadata resources for information about research data metadata.

4. Significant challenges and surprises can arise when it comes to making research data accessible. How do you describe an image of seismic lines in a meaningful way? Can sound files help visually-impaired users engage with seismic data? Can the librarians encourage such use of the sound files with improved metadata? Can accessibility metadata be incorporated into Dublin Core to help with discovery and access ("DCMI," n.d.)? The librarians believe that traditional metadata improves accessibility, but more research in this area is needed. Many interesting questions remain around accessible data, and in particular, about how to optimize item-level metadata in order to help support 
accessibility in different online contexts and for different kinds of online resources, such as research data.

5. In early 2017, Dr. Lankston revised several of the narratives. A recent evaluation, conducted while writing this article, revealed that a few of the revised narratives, which now include some photographs of the original research team, may not be fully accessible. The librarians will need to remediate these files. Accessibility adds a new dimension to ongoing maintenance issues around online digital content.

6. Making historical datasets available to current researchers, with quality metadata, is worthwhile. Even with imperfect metadata, as of early November 2017 the seismic survey data files had been downloaded collectively nearly 3,300 times. The librarians feel encouraged by the number of downloads and hope that one or more researchers might be using this old data in new ways.

7. The missing documentation about the original survey and the subsequent difficulties related to creating the metadata highlights for all librarians the value of becoming involved in current research projects at the earliest possible time in order to ensure that researchers create good documentation during the research process. It is difficult enough for researchers to accurately recall their methods and decisions after-the-fact and basically impossible for external stakeholders such as librarians. Active research data management is essential for the production of accurate, thorough metadata that helps facilitate the future discovery and re-usability of data.

8. At the risk of undermining the latter lesson, the authors recognize that working with experts outside the library may pose challenges. The authors feel fortunate that Dr. Lankston remained such a willing and consistently communicative partner for the duration of this project and that the project did not require a hard deadline. Communication 
difficulties and time constraints can complicate the best intentions to work cooperatively.

Dr. Lankston also addressed the Metadata Librarian's questions without complaint or hesitation. The authors suspect that in some cases, librarians and outside experts will value different kinds of information in different ways. Reaching agreement on a "quality metadata record" may require some extra effort and explanation by the librarian, and potentially, some compromise. Presumably, disagreements about metadata will also require time to resolve, so working with outside experts will likely add time to the project timeline.

Nevertheless, the authors remain positive about the outcomes of working with outside experts. The knowledge, vocabulary, and perspectives that they contribute can really enhance the discoverability and understandability of a dataset, and as data are increasingly recognized as significant research products, worthy of curation, it seems inevitable that librarians will need to become comfortable working with experts outside the library on a regular basis in order to adequately describe and provide access to them.

\section{Conclusion}

This seismic dataset presented a number of challenges for the librarians, neither of whom had a background in geosciences or any experience with metadata for research data. Still, they successfully made the data available - with significant assistance from Dr. Lankston - and consider the project a success. They hope that sharing this use case will help other small- to medium-sized institutions move forward with adding datasets to their collections. Given the continued development of disciplinaryspecific research data metadata schemas within the last few years, the librarians hope that others will encounter fewer challenges related to describing datasets. 


\section{References}

About the University of Montana. (n.d.). Retrieved October 23, 2017, from

http://www.umt.edu/about

Beyene, W. M. (2017). Metadata and universal access in digital library environments. Library Hi Tech, 35(2), 210-221. https://doi.org/10.1108/LHT-06-2016-0074

Beyene, W. M., \& Godwin, T. (2018). Accessible search and the role of metadata. Library Hi Tech. https://doi.org/10.1108/LHT-08-2017-0170

British Geological Survey. (n.d.). Interpreted seismic and well data - Datasets. Retrieved October 23, 2017, from https://data.gov.uk/dataset/interpreted-seismic-and-well-data

Chao, T. (2015). Mapping methods metadata for research data. International Journal of Digital Curation, 10(1), 82-94, doi: https://doi.org/10.2218/ijdc.v10i1.347

Chapman, A., Kelly, B., Nevile, L., \& Heath, A. (2006). Personalization and accessibility: Integration of library and web approaches. In Proceedings of the 15th International Conference on World Wide Web (pp. 871-872). https://doi.org/10.1145/1135777.1135920

Chiware, E., \& Mathe, Z. (2015). Academic libraries' role in research data management services: A South African perspective. South African Journal of Library and Information Science, 81(2), 1.

Collection development policy. (2011). Retrieved October 23, 2017, from https://www.lib.umt.edu/files/Mansfield-Library Collection-Development-Policy-2011-05.pdf

DCMI: DCMI accessibility community. (n.d.). Retrieved November 14, 2017, from http://www.dublincore.org/groups/access/standards/

Dell'Aversana, P. (2013). Listening to geophysics: Audio processing tools for geophysical data 
analysis and interpretation. The Leading Edge, 32(8), 980-987, doi:

https://doi.org/10.1190/tle32080980.1

Ferguson, J. (2012). Description and annotation of biomedical data sets. Journal of eScience Librarianship, 1(1), 51-56, doi: http://dx.doi.org/10.7191/jeslib.2012.1000

Gonzalez, A., \& Peres-Neto, P. R. (2015). Data curation: Act to staunch loss of research data. Nature International Weekly Journal of Science, 520, 436, doi: https://doi.org/10.1038/520436c

Image description guidelines - DIAGRAM Center. (n.d.). Retrieved November 14, 2017, from http://diagramcenter.org/table-of-contents-2.html

Keenan, T. (2014). Impacts of Metadata on Accessibility of Digital Collections. PowerPoint presented at the OLAC-MOUG Conference, Kansas City, Missouri. Retrieved January 20, 2018, from https://scholarworks.umt.edu/ml pubs/18

Lage, K., Losoff, B., \& Maness, J. (2011). Receptivity to library involvement in scientific data curation: A case study at the University of Colorado Boulder. Portal: Libraries and the Academy, 11(4), 915937. doi: https://doi.org/10.1353/pla.2011.0049

Lee, D. J., \& Stvilia, B. (2017). Practices of research data curation in institutional repositories: A qualitative view from repository staff. PLOS ONE, 12(3), e0173987. https://doi.org/10.1371/journal.pone.0173987

Morozumi, A., Nagamori, M., Nevile, L., \& Sugimoto, S. (2006). Using FRBR for the selection and adaptation of accessible resources. International Conference on Dublin Core and Metadata Applications, 0(0). Retrieved from http://dcpapers.dublincore.org/pubs/article/view/850

National Geospacial Data Center. (n.d.). ECS data management - Metadata. Retrieved October 23, 2017, from https://www.ngdc.noaa.gov/mgg/ecs/metadata/seismic/ 
Newton, M. P., Miller, C. C., \& Bracke, M. S. (2010). Librarian roles in institutional repository data set collecting: Outcomes of a research library task force. Collection Management, 36(1), 53-67. doi: https://doi.org/10.1080/01462679.2011.530546

Perrier, L., Blondal, E., Ayala, A. P., Dearborn, D., Kenny, T., Lightfoot, D., ... MacDonald, H. (2017). Research data management in academic institutions: A scoping review. PLoS ONE, 12(5). doi: https://doi.org/10.1371/journal.pone.0178261

Pesce, Valeria. (2015). How to describe a dataset: Interoperability issues [PowerPoint slides].

Retrieved November 18, 2017 from https://www.slideshare.net/valeriap/how-to-describe-adataset-interoperability-issues

Poole, A. H. (2016). The conceptual landscape of digital curation. Journal of Documentation, 72(5), 961986. doi: https://doi.org/10.1108/JD-10-2015-0123

Qin, J., Dobreski, B., \& Brown, D. (2016). Metadata and reproducibility: A case study of gravitational wave research data management. International Journal of Digital Curation, 11(1), 218-231, doi: https://doi.org/10.2218/ijdc.v11i1.399

Schubert, C., Shorish, Y., Frankel, P., \& Giles, K. (2013). The evolution of research data: strategies for curation and data management. Library Hi Tech News, 30(6), 1-6. doi: https://doi.org/10.1108/LHTN-06-2013-0035

United States Geological Survey. (2017). Prepare metadata files for upload to National Digital Catalog. Retrieved November 9, 2017, from https://datapreservation.usgs.gov/page/prepare_metadata_for_NDC

Walker, W., \& Keenan, T. (2015). Do you hear what I see? Assessing accessibility of Digital Commons and CONTENTdm. Journal of Electronic Resources Librarianship, 27(2), 69-87. 
WebAIM. (2017). Introduction. Retrieved November 7, 2017, from https://webaim.org/techniques/alttext/

World Wide Web Consortium (W3C). (2008). Web content accessibility guidelines (WCAG) 2.0. Retrieved January 18, 2018, from http://www.w3.org/TR/WCAG20/\#guidelines

Yu, F., Deuble, R., \& Morgan, H. (2017). Designing research data management services based on the research lifecycle - A consultative leadership approach. Journal of the Australian Library and Information Association, 66(3), 287-298.

Yu, H. H. (2017). The role of academic libraries in research data service (RDS) provision: Opportunities and challenges. The Electronic Library, 35(4), 783-797. https://doi.org/10.1108/EL-10-2016-0233 